\title{
Development of Infra-red based Opto Electronic Measurement System for Planter Seed Spacing under Laboratory Conditions
}

\author{
A. Jany Giles ${ }^{1 *}$, A. Surendrakumar ${ }^{2}$, B. Shridar ${ }^{2}$ and D. Asokan ${ }^{2}$ \\ ${ }^{I}$ Department of Farm Machinery and Power Engineering, AEC\&RI, Kumulur, India \\ ${ }^{2}$ Department of Farm Machinery and Power Engineering, AEC\&RI, TNAU \\ Coimbatore, India \\ *Corresponding author
}

Keywords

Precision planters, Opto electronic measurement, Experimental test rig, Greased belt test

Article Info

Accepted:

10 January 2021

Available Online:

10 February 2021

\section{A B S T R A C T}

Successful operation of precision planters involves various stages. The testing is an important stage in development of precision planter. In order to provide accurate and several data, an opto electronic measurement system was developed to test the performance of precision planters. It was evaluated with greased belt test rig for real measurements and tested under laboratory conditions for two varieties of maize CO 6 and CO H M 8 seeds. The coefficient of determination, mean absolute percentage error, absolute difference, intercept and slope were found out for two varieties of maize seeds by linear regression respectively as 0.9982 and $0.9987,2.21$ and $2.49,0.3882$ and $0.4576,-0.191$ and $-0.139,0.99982$ and 0.99937. The opto electronic measurement system eliminates the human errors and complex calibration procedures as well as saves the time and labour requirement.

\section{Introduction}

The vital component in precision planting of maize is maintaining the plant spacing uniformly throughout the planting process. To ensure the uniform plant spacing and planting depth, precision seeding is viable technology in maize planting. It results in higher growth and yield towards lesser labor cost of seeding. For achieving higher seeding performance and stability in higher speeds the seed metering device of precision planter plays an important role (Liang et al., 2015).
The design and construction of seed metering device from laboratory to field involves tedious process. Through these process stages, the seed drill test rig is an important component. It helps in testing and evaluating the design and construction of precision seed metering device. The measurement systems used in test rig has subjected to improvements throughout the development phases. Earlier, field and soil bin studies were conducted to measure the performance of seed metering devices(Allen and Hollingsworth, 1979; Barrett et al., 1983). After planting with seed 
metering devices, the seeds were dug out and seed spacing were measured. These measurements were influenced by seed bed characteristics, weather conditions, plant emergence factors, weeds and seed drill performance effects viz., drop points, seed bounces, rolls. The difficulty of these methods is time involved in digging and locating small seeds without disturbing their locations (Lan et al., 1999).

The sticky belt method is used to measure seed spacing in laboratory conditions by overcoming the factors in field and soil bin studies. Among those advantages there are some limitations present in this method viz., no of seed spacing measurements done by single run which is limited by length of the belt, accuracy of measurement influenced by human errors, time involved in whole process and probability of sliding of seeds during higher travelling speed of sticky belt(Kocher et al., 1998).

Opto electronic measurement system used for seed spacing measurement to overcome the limitations experienced by the sticky belt method i.e., limitation of number of measurements, precision of measurement (Davut Karayel and Özmerzi, 2004; Kocher et al., 1998; Lan et al., 1999; Müller et al., 1994; Özmerzi et al., 2002). It has reduced the labor requirement involved in seed spacing measurement, although at higher frequencies of seed dropping the accuracy of seed spacing measurement was reduced (Karayel et al., 2006). To reduce the errors involved in the opto electronic measurement system, the high speed camera system and image processing was used (Drake, 1991). Karayel et al., (2006) employed high speed camera to observe wheat and soybean seed space uniformity and velocity of falling seeds from fluted roller seed metering mechanism. By using camera system, increase of collected sample sizes and reduction of surplus seed has achieved. Zhan et al., (2010) evaluated the performance of vacuum cylinder for sowing rape seeds and investigated the seed motion influenced by positive pressure. Due to the advancement of high speed camera systems and image processing techniques, electric seed metering systems equipped with these to identify seed singulation errors in real time (Mangus et al., 2017). Amongst advancements, these methods needs the complex calibration and data processing methods, greater human power and higher hardware costs (Karayel et al., 2006).

Precision planter performance test methods are defined in ISO 7256-1:1984(E) Standard, 1984. Performance test methods are essential in development and testing process among agricultural machine manufacturers. In order to serve this need it is required to design and development of suitable testing platform for precise and rapid measurement while achieving reduction in time and labor requirement

The recent development of optical sensors led to rapid industrial automation and measurement due to the advantages viz., high sensitivity and fast response time, ease of use and data acquisition (Cay et al., 2017). Kocher et al., (1998) developed opto electronic system consisting light emitting diodes and photo transistors to measure time between seed drop and location of seed drop reference to planter. The measured seed spacing from opto electronic system compared to greased belt system and these correlated to front-back locations of dropping seeds reference to planter. Hajahmed et al., (2011) developed opto electronic monitoring system for chick pea seed metering unit. The linear relationship between system measured and actual measured was studied. Cay et al., (2017) developed an opto electronic measurement system for precision planters and the seed spacing values from developed 
system checked with greased belt system and physical properties of seeds.

Hence it was decided to develop opto electronic measurement system using optical sensors i.e., infra-red sensors for inclined plate seed metering mechanism and evaluate against the greased belt system.

\section{Materials and Methods}

\section{Seed}

Opto electronic measurement system aimed to design independently with various seed metering mechanisms and seeds. In this study maize seeds of two varieties were taken for study. Photogrammetry studies were done to analyze the maize seed length, breadth, thickness, area, equivalent diameter, sphericity and roundness. The results were given in Table 1.

$$
\text { Sphericity }=\frac{d_{\tilde{i}}}{d_{e}}
$$$$
\text { Roundness }=\frac{A_{p}}{A_{e}}
$$

Where $d_{i}$ is the diameter of largest inscribing circle, $d_{c}$ diameter of the smallest circumscribing circle, ${ }^{A_{p}}$ is the projected area of the seed, $A_{c}$ is the area of smallest circumscribing circle.

\section{Optoelectronic measurement system}

Optoelectronic measurement system equipped with Infrared sensors, a microcontroller, an optical rotary encoder, computer for processing the data. Functional block diagram of system is shown in Fig. 1. Infrared sensor system consists 3 pairs of infra-red transmitting and receiving tubes. If transmitted light meets the falling seeds, transmitted light reflect back and received by receiving tubes. The effective sensing distance range was 2 to $30 \mathrm{~cm}$ and detection angle was $35^{\circ}$. The infra-red sensor was placed at minimum distance of height from greased belt $(20$ to $50 \mathrm{~mm}$ ) to reduce the errors of seed spacings by relative motion. The microcontroller equipped in the system was ATmega328P. It has 14 digital I/O pins, 6 analog I/O pins, $16 \mathrm{MHz}$ clock and flash memory of $32 \mathrm{~KB}$. The optical rotary encoder of incremental type with quadrature outputs attached with system to measure the distance between seed drops. It has resolution of 400 Pulses Per Revolution. Computer was equipped with open source Arduino IDE. Through UART serial communication protocol, it records the signals from rotary encoder and infra-red sensor system. By analyzing the recorded data, the seed spacings were measured.

\section{Experimental test rig}

The test rig equipped with sticky belt, inclined plate metering system, variable speed DC motors with controllers and opto electronic measurement system. Schematic diagram of experimental test rig is shown in Fig. 2. The sticky belt has the measurable length of $1935 \mathrm{~mm}$, width of $475 \mathrm{~mm}$ and thickness of $2 \mathrm{~mm}$. Sticky belt was driven by pair of rollers of $50 \mathrm{~mm}$ diameter from AC variable speed motor through v-belt transmission ratio of 2.7:1. Inclined plate metering system was mounted above greased belt and inclined plate seed metering plate was attached to stepper motor. The stepper motor has $5.6 \mathrm{~kg} \mathrm{~cm}$ torque, $12 \mathrm{~V}$ operating voltage and controlled by 4 Amperes, 16 micro step stepper motor drive attached to ATmega328p microcontroller. The developed opto electronic measurement system was attached to inclined plate metering system. To measure the travelling speed of greased belt rotary encoder was attached to spring 
tensioned wheel which was running on belt. Instead of attaching rotary encoder to driving motor or driven shaft of greased belt, the rotary encoder was equipped to travel on surface of belt. It helps to measure the actual travelling speed of belt without slippage between driving rollers and greased belt. To avoid rolling of wheel attached to rotary encoder on greased surface of belt, care has been taken to apply grease on center of the belt and wheel runs on side of the belt. To ensure the accuracy of system two micro controllers were used. Both of them were attached to rotary encoder. The stepper motor and infra-red sensor module was separately attached to each micro controllers. Seed spacing data were taken from microcontrollers which were attached to infrared sensor module.

\section{Measurement of seed spacing}

The sticky belt testing platform with opto electronic measurement system was operated at the speed of $1.5 \mathrm{kmph}$ with the seed spacing varying from 5 to $45 \mathrm{~cm}$. To achieve desirable seed spacing inclined metering plate was operated at 0.10 to $0.20 \mathrm{~ms}^{-1}$ and pulses for stepper motor configured in the microcontroller as desired seed spacing. The seed spacing readings were measured on greased belt using measuring scale and digital caliper. The values measured manually from greased belt taken as reference values. The available length for measuring seed spacing in belt is $1.9 \mathrm{~m}$. Hence every spacing interval of 2 and $3 \mathrm{~cm}$, maximum of five to four seed spacing readings were taken. Totally 85 seed spacing readings were taken for each variety. The studies were done for two selected varieties. The relationship was analyzed between greased belt and opto-electronic system readings(D. Karayel et al., 2006; Kocher et al., 1998; Lan et al., 1999).The mean absolute percentage error (MAPE) and absolute difference value $\left(\mathrm{e}_{\mathrm{i}}\right)$ were found out for two varieties and compared. For the good system performance the high coefficient of determination $\left(\mathrm{R}^{2}\right)$, low MAPE and $\mathrm{e}_{\mathrm{i}}$, minimum value of intercept $\left(\beta_{0}\right)$ as close to zero and closer value of slope $\left(\beta_{1}\right)$ to one, are the indicators. The mean absolute percentage error and absolute difference value were found out using by following equations (Cay et al., 2017).

$$
\begin{aligned}
& \text { MAPE }=\left(\frac{100}{n}\right) \sum_{i=1}^{n}\left|\frac{O S_{i}-R S_{i}}{R S_{i}}\right| \ldots \\
& e_{i}=\left|O S_{i}-R S_{i}\right|
\end{aligned}
$$

Where $O S_{i \text { is }}$ value of seed spacing by developed opto electronic measurement system and $R S_{i}$ is value of seed spacing of measurement from sticky belt.

Initially for 30 seconds, the test rig has made to run ideally to reach steady state of travelling speed. It helps to acquire the seed spacings on specified travel speed of greased belt which respect to adjusted seed spacings by opto electronic measurement system.

\section{Results and Discussion}

The relationship between seed spacings measured from greased belt with reference to adjusted seed spacings by developed optoelectronic measurement system is shown in Fig. 3. It shows relationship of seed spacings of the maize two varieties $\mathrm{CO} 6$ and $\mathrm{CO} \mathrm{H} \mathrm{M}$ 8 . The results of regression analysis, absolute difference and MAPE of two varieties of maize are shown in Table 1 . The coefficient of determination $\left(\mathrm{R}^{2}\right)$ for CO 6 and CO H M 8 maize varieties were 0.9987 and 0.9982 . These higher coefficients indicate the data meets their assumptions and shows ability to determine real measurement values. The intercept $\left(\beta_{0}\right)$ values for two varieties of maize were -0.191 and -0.139 . These values are closer to 0 . The slope $\left(\beta_{1}\right)$ values for two 
varieties of maize were 0.99982 and 0.99937 . These values are closer to 1. Cay et al., 2017 studied the opto electronic measurement system consist optical sensors for seed detection with greased belt system and found that coefficient of determination $\left(\mathrm{R}^{2}\right)$ were 0.992 to 1.00 for the various seeds. The intercept $\left(\beta_{0}\right)$ and slope $\left(\beta_{1}\right)$ values were found out as varied between -0.331 to +0.471 and 0.998 to 1.021 respectively. D. Karayel et $a l ., 2006$ used high speed camera system to detect wheat and soybean and coefficient of determination were found out as 0.96 and 0.97 respectively. Kocher et al., 1998 used photo transistors to measure seed spacing and coefficient of determination was reported as 0.977. The cause of lower coefficient of determination was stated as seed size of $3 \mathrm{~mm}$ or smaller.

To assess the precision of developed opto electronic measurement system Mean absolute percentage error (MAPE) and absolute difference $\left(e_{i}\right)$ were studied (Table 2 ). The MAPE and $e_{i}$ found out for seed spacings measured by greased belt system and developed opto electronic measurement system. The Mean absolute percentage error (MAPE) for CO 6 and CO H M 8 were 2.21 and 2.49 per cent respectively. These values are acceptable as low in accordance with the study done by Cay et al., 2017 as 2.86 to 4.78 per cent while considering multiple seeds. The absolute difference $\left(e_{i \bar{i}}\right)$ for CO 6 and CO $\mathrm{H} \quad \mathrm{M} \quad 8$ were 0.3882 and $0.4576 \mathrm{~cm}$ respectively. These shown that the measured values using opto electronic system are closer to measured values using greased belt system as reported as 0.25 to $0.65 \mathrm{~cm}$ for multiple seeds by Cay et al., 2017.

The ANOVA done on measured seed spacings by greased belt with seed varieties and adjusted seed spacings of opto electronic measurement system (Table 3). The effect of adjusted seed spacings on greased belt seed spacings is statistically significant as $\mathrm{P}$ value (0.000) was low as significant level $(\alpha=$ $0.05)$. The varieties of seeds has no effect on seed spacings measured by opto electronic measurement system as $\mathrm{P}$ value (0.594) greater than significant level $(\alpha=0.05)$.

Table.1 Physical properties of maize seeds of CO 6 and CO H M 8 varieties

\begin{tabular}{|c|l|c|c|}
\hline S. No. & \multicolumn{1}{|c|}{ Properties } & CO 6 & CO H M 8 \\
\hline $\mathbf{1 .}$ & Length, mm & $9.920 \pm 0.788$ & $9.532 \pm 0.731$ \\
\hline $\mathbf{2 .}$ & Breadth, mm & $8.472 \pm 0.713$ & $8.485 \pm 0.384$ \\
\hline $\mathbf{3 .}$ & Thickness, $\mathrm{mm}$ & $6.217 \pm 0.845$ & $6.257 \pm 0.787$ \\
\hline $\mathbf{4 .}$ & Area, $\mathrm{mm}^{2}$ & $62.799 \pm 8.462$ & $60.519 \pm 5.878$ \\
\hline $\mathbf{5 .}$ & Equivalent diameter, mm & $8.048 \pm 0.412$ & $7.977 \pm 0.380$ \\
\hline $\mathbf{6 .}$ & Sphericity & $0.804 \pm 0.077$ & $0.809 \pm 0.036$ \\
\hline $\mathbf{7 .}$ & Natural rest position & & \\
\hline $\mathbf{8 .}$ & Vertical position & $0.675 \pm 0.103$ & $0.663 \pm 0.096$ \\
\hline $\mathbf{9 .}$ & Roundness & $0.782 \pm 0.065$ & $0.807 \pm 0.059$ \\
\hline $\mathbf{1 0 .}$ & Thousand seed weight, $\mathrm{g}$ & $358.23 \pm 10.740$ & $397.45 \pm 9.670$ \\
\hline
\end{tabular}

Value $=$ Mean \pm SD 
Table.2 Results of regression analysis and absolute difference

\begin{tabular}{|l|c|c|c|c|c|}
\hline \multicolumn{1}{|c|}{ Variety } & $\boldsymbol{\beta}_{\mathbf{0}}$ & $\boldsymbol{\beta}_{\mathbf{1}}$ & $\mathbf{R}^{\mathbf{2}}$ & $\boldsymbol{e}_{i}(\mathbf{c m})$ & MAPE (\%) \\
\hline CO 6 & -0.191 & 0.99982 & 0.9987 & 0.3882 & 2.21 \\
\hline CO H M 8 & -0.139 & 0.99937 & 0.9982 & 0.4576 & 2.49 \\
\hline
\end{tabular}

Table.3 Analysis of variance, of seed spacings from CO 6 and CO H M 8 varieties and adjustedspacing by opto electronic measurement system with seed spacing measured in greased belt

\begin{tabular}{|l|c|c|c|c|c|}
\hline \multicolumn{1}{|c|}{ Source } & DF & Adj SS & Adj MS & F-Value & P-Value \\
\hline Variety & 1 & 0.1 & 0.07 & 0.29 & 0.594 \\
\hline Adjusted spacing & 16 & 25493.5 & 1593.34 & 6323.53 & 0.000 \\
\hline Variety x Adjusted spacing & 16 & 2.1 & 0.13 & 0.51 & 0.937 \\
\hline Error & 136 & 34.3 & 0.25 & & \\
\hline Total & 169 & 25529.9 & & & \\
\hline
\end{tabular}

Fig.1 Functional block diagram of opto electronic measurement system with electro mechanical seed drive system

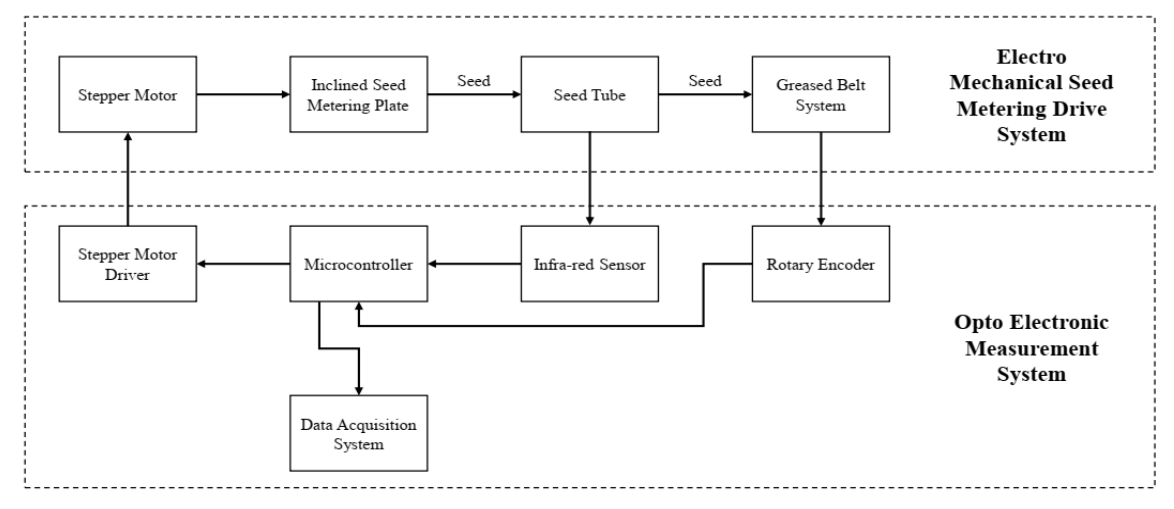

Fig.2 Schematic diagram of experimental test rig

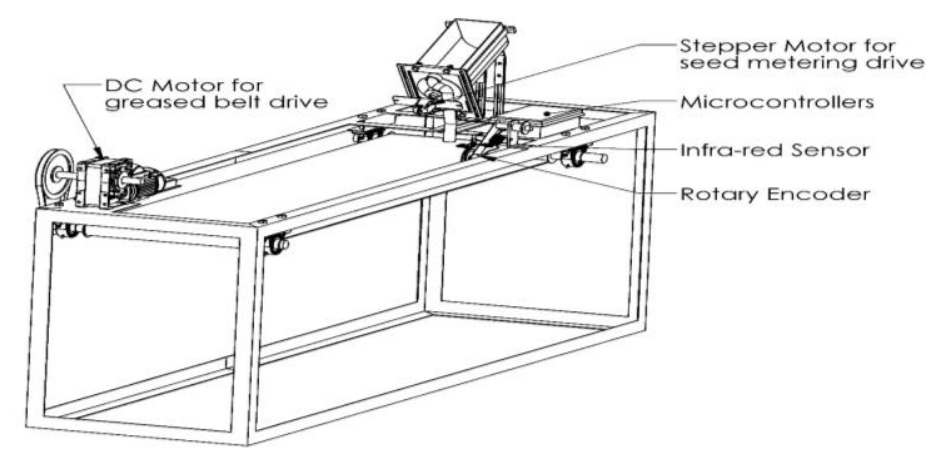


Fig.3 Relationship between seed spacing measured from greased belt and adjusted seed spacing of opto electronic measurement system

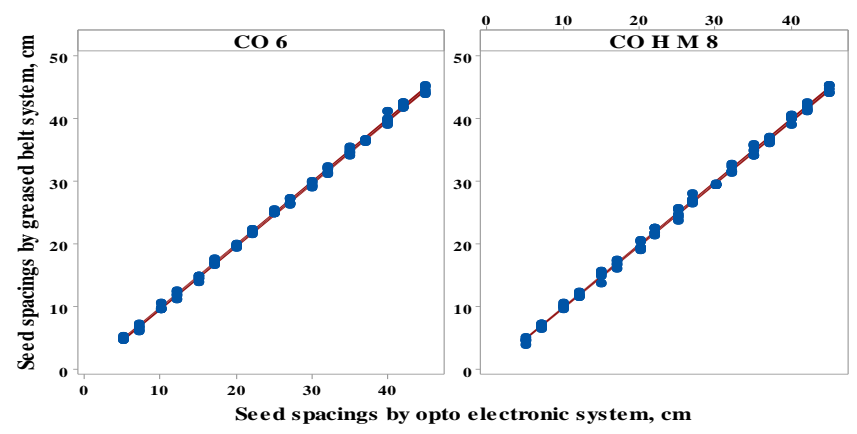

Fig.4 Residual plots of seed spacings measured from greased belt system
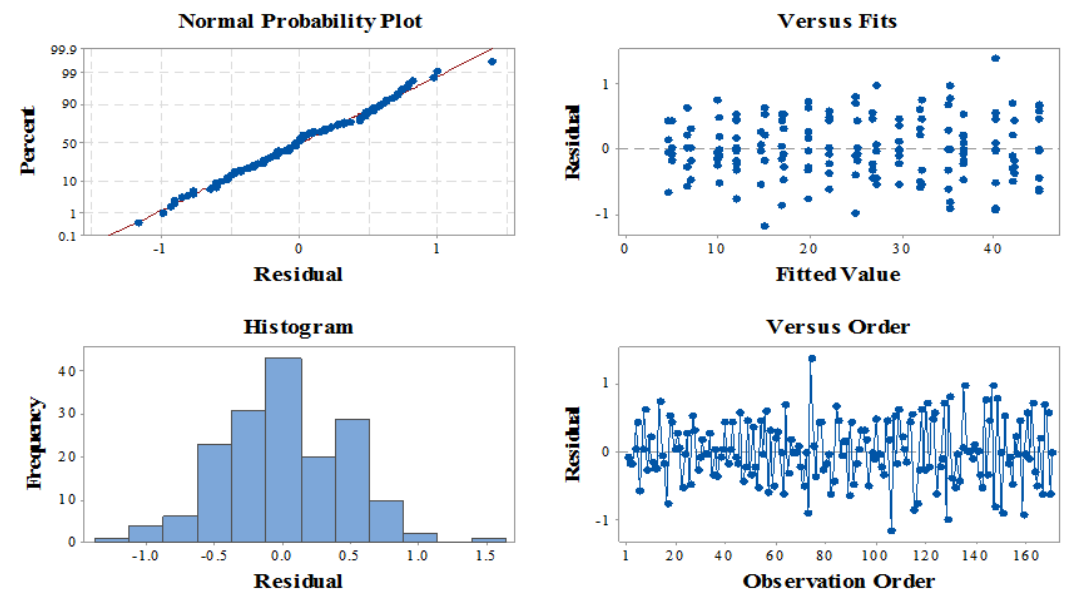

Residual is the difference between a seed spacing value and the mean of all seed spacing values in the group. If residual is positive then the corresponding seed spacing value is greater than the sample mean, and is negative when the seed spacing value is less than the sample mean. The residual plots of seed spacings measured by greased belt system are shown in Fig. 4. In normal probability plot the values were following the straight line. It shows that the residuals are normally distributed and meeting the assumptions. In Residuals versus fits plot the residuals are randomly distributed and have constant variance. Hence the assumptions of data were achieved. Whereas in residuals versus order plot, the residuals are randomly

distributed from one another and does not show any relationships between them. It shows that the residuals are independent from one another.

Measurement of seed spacing by developed opto electronic system were successful for the two varieties of maize seeds. The coefficient of determination $\left(\mathrm{R}^{2}\right)$ for two varieties of maize were 0.9982 and $0.9987, \mathrm{P}$ value of anova is 0.000 , Mean absolute percentage error (MAPE) were 2.21 and 2.49, the intercept $\left(\beta_{0}\right)$ values for two varieties of maize were -0.191 and -0.139 , the slope $\left(\beta_{1}\right)$ values for two varieties of maize were 0.99982 and 0.99937. The errors in seed spacing measurements (absolute difference $\left({ }^{e_{i}}\right)$ ) were 
low as 0.3882 and 0.4576 . Hence the accurate seed spacing measurements as were done by real measurements can be done by developed opto electronic measurement system.

In conclusion to evaluate the precision of seed planters, an opto electronic measurement system was developed. It was tested under laboratory conditions for two varieties of maize $\mathrm{CO} 6$ and $\mathrm{CO}$ H M 8 seeds against the measurements taken by greased belt system. The coefficient of determination, mean absolute percentage error, absolute difference, intercept and slope were found out for two varieties of maize seeds by linear regression respectively as 0.9982 and $0.9987,2.21$ and $2.49,0.3882$ and $0.4576,-0.191$ and -0.139 , 0.99982 and 0.99937 . The developed opto electronic measurement system provides the accurate and fast measurement values. It eliminates the human errors and complex calibration procedures as involved in other measurement systems. It saves the time and labour requirement as present in other measurement systems i.e., greased belt system, high speed camera system. The developed opto electronic measurement system can provide non intermittent and limitless measurements as not available in greased belt system where measurements limited by the length of belt. Hence the developed opto electronic measurement system can be used to test the performance of precision seed planters under laboratory conditions.

\section{Acknowledgements}

The data used in this work comprise a part of the research project supported by the Council of Scientific and Industrial Research, New Delhi, India. In addition, authors are thankful to Council of Scientific and Industrial Research, New Delhi, India for supporting this research project.

\section{References}

Allen, R. R., and Hollingsworth, L. D. (1979). Sunflower Planting and Stand Establishment With Coated Seed. Paper - American Society of Agricultural Engineers, 665-668.

Barrett, J. R., Jacko, R. B., and Sumner, H. R. (1983). Planter Selection Accuracy for Edible Beans. Transactions of the American Society of Agricultural Engineers, 26(2), 367-371. https://doi.org/10.13031/2013.33939

Cay, A., Kocabiyik, H., Karaaslan, B., May, S. and Khurelbaatar, M. (2017). Development of an opto-electronic measurement system for planter laboratory tests. Measurement: Journal of the International Measurement Confederation, 102, 90-95. https://doi.org/10.1016/j.measurement.2 017.01 .060

Drake, T. G. (1991). Granular flow physical experiments and their implications for microstructural theories. Journal of Fluid Mechanics, 225, 121-152. https://doi.org/10.1017/S002211209100 1994

Hajahmed, O., Tola, E., Al-Gaadi, K. A. and Kheiralla, A. F. (2011). Development of an Opto-Electronic Monitoring System for Crop Planter Seed Metering Unit. Middle-East Journal of Scientific Research, 8 (4)(4), 732-738.

ISO 7256-1:1984(E) Standard. (1984). Sowing equipment-test methods e Part one, single seed drills (precision drills). International Organisation for Standardization. Geneva, Switzerland.

Karayel, D., Wiesehoff, M., Özmerzi, A., and Müller, J. (2006). Laboratory measurement of seed drill seed spacing and velocity of fall of seeds using highspeed camera system. Computers and Electronics in Agriculture, 50(2), 8996. 
https://doi.org/10.1016/j.compag.2005.0 5.005

Karayel, Davut, and Özmerzi, A. (2004). Effect of forward speed on hill dropping uniformity of a precision vacuum seeder. HortTechnology, 14(3), 364 367.

https://doi.org/10.21273/horttech.14.3.0 364

Kocher, M. F., Lan, Y., Chen, C., and Smith, J. A. (1998). Opto-electronic sensor system for rapid evaluation of planter seed spacing uniformity. Transactions of the American Society of Agricultural Engineers, 41(1), 237-245. https://doi.org/10.13031/2013.17143

Lan, Y., Kocher, M. F., and Smith, J. A. (1999). Opto-electronic sensor system for laboratory measurement of planter seed spacing with small seeds. Journal of Agricultural and Engineering Research, 72(2), 119-127. https://doi.org/10.1006/jaer.1998.0353

Liang, Z., Zhang, D., Yang, L., Cui, T., and Hao, Y. (2015). Experimental study on motor driven pneumatic precision seedmetering device for maize. American Society of Agricultural and Biological Engineers Annual International Meeting 2015, 5, 3945-3952. https://doi.org/10.13031/aim.201521897 58

Mangus, D. L., Sharda, A., Flippo, D. Strasser, R., and Griffin, T. (2017). Development of high-speed camera hardware and software package to evaluate real-time electric seed meter accuracy of a variable rate planter. Computers and Electronics in Agriculture, 142, 314-325. https://doi.org/10.1016/j.compag.2017.0 9.014

Müller, J., Rodrigues, G., and Köller, K. (1994). Optoelectronic measurement system for evaluation of seed spacing. AGENG Meeting Milano.

Özmerzi, A., Karayel, D., and Topakci, M. (2002). Effect of sowing depth on precision seeder uniformity. Biosystems Engineering, 82(2), 227-230. https://doi.org/10.1006/bioe.2002.0057

Zhan, Z., Yaoming, L., Jin, C., and Lizhang, $X$. (2010). Numerical analysis and laboratory testing of seed spacing uniformity performance for vacuumcylinder precision seeder. Biosystems Engineering, 106(4), 344-351. https://doi.org/10.1016/j.biosystemseng. 2010.02.012

\section{How to cite this article:}

Jany Giles, A., A. Surendrakumar, B. Shridar and Asokan, D. 2021. Development of Infra-red based Opto Electronic Measurement System for Planter Seed Spacing under Laboratory Conditions. Int.J.Curr.Microbiol.App.Sci. 10(02): 1387-1395. doi: https://doi.org/10.20546/ijcmas.2021.1002.166 